\title{
The displacement effect of convenience: the case of recycling
}

\author{
Andrew Abbott, Shasikanta Nandeibam, Lucy O’Shea
}

\begin{abstract}
In light of increasingly ambitious recycling targets it is important to analyse the potential displacement effect of improving access to kerbside provision on other forms of recycling. Do households view the different modes of recycling as substitutes or complements of each other? Does this perceived relationship depend on the type of material recycled? Using data for all of the UK's local governments from 2004Q2 to 2013Q3 we analyse the nature of the relationship between the two main channels of recycling. In the case of dry recycling, the empirical findings are ambiguous on the trade-off between kerbside and non-kerbside recycling. On the one hand, the findings suggest that there is no trade-off when considering the effect of expanding kerbside provision. On the other hand, the findings also suggest that there is a trade-off when we focus on the effect of expanding non-kerbside provision. However, putting together the empirical findings with theory (in particular, the symmetry property of the Hicksian substitution effect) suggests that there is a trade-off irrespective of whether we consider expansion of kerbside or non-kerbside provision. In the case of green (compost) recycling the empirical findings on their own or together with theory unambiguously suggest that there is a trade-off.
\end{abstract}

Key words: recycling; substitutability; gross substitutability; waste policy.

JEL classification: O18; Q58; R11; R15

(C) 2017. This manuscript version is made available under the CC-BY-NC-ND 4.0 license http://creativecommons.org/licenses/by-nc-nd/4.0/ 


\section{Introduction}

From a household perspective the single biggest factor contributing to the convenience of recycling has been the improved provision of recycling services at the kerbside. However, local drop-off recycling centres still remain an important component of the recycling infrastructure. Therefore, an interesting question to ask is to what extent households view these different channels of recycling service provision as substitutable or complementary. The total proportion of waste recycled and the split between the various channels can change, depending on the recyclability of materials and households’ propensity to undertake recycling. Propensity to recycle via a particular channel may be affected positively or negatively by recycling behaviour through other channels. Such positive and negative effects can be due to enhanced awareness or due to subtractability and moral licencing (Merritt et al., 2010). Subtractability relates to the physical constraint that a single container cannot be recycled simultaneously through different channels. Moral licensing occurs across different domains of behaviour. For example, in relation to recycling and public transport, individuals may hold the view that because they recycle they are entitled not to use public transport. Likewise, within a single domain like recycling, individuals may feel they do enough recycling at the kerb so that any further waste separation is not required.

A key factor in explaining recycling behaviour appears to be the provision of kerbside collection schemes (e.g. Callan and Thomas, 1997; Dahlén, 2007; Jenkins et al., 2003; Kinnaman and Fullerton, 2000; Larsen, 2010; Sidique et al., 2010a). Also important are the specific attributes of the scheme, such as convenience (Ando and Gosselin, 2005) and the size of the recycling container or the frequency of recycling and residual waste collections (Abbott et al., 2011; WRAP, 2009; 2010b; WYG Environment, 2012). Other contributions have sought to examine the nature of spillovers between various policies to enhance recycling or reduce waste. Jenkins et al. (2003) find a positive marginal effect for recycling at both the kerbside and local drop-off centres for a range of materials, with the incremental effect being smaller for materials for which alternative recycling options are already in place. Using data from California’s Department of Conservation, Beatty et al. (2007) consider the marginal effect of expanding kerbside provision on quantities recycled by households at the kerb, at recycling centres and on overall recycling quantity. The overall benefits of kerbside 
recycling are found to be small, since improved recycling volumes from providing kerbside collections are offset by lower returns at recycling centres. Sidique et al. (2010) find contradictory evidence of a trade-off, where in one case they hypothesise a complementary relationship between kerbside and non-kerbside recycling (Sidique et al., 2010a), whereas in another, they find no evidence of any relationship between them (Sidique et al., 2010b).

In this paper, we develop a theoretical model to understand better the interactions between different recycling behaviours. We complement the approach taken by D’Amato et al. (2016), who examine the relationship between waste reduction and recycling behaviours. ${ }^{1}$ We provide a bridge between the notion of a substitution/complement relationship and empirically available data on volumes of recycling. Although the context is recycling, our analysis has a broader policy reach. Whatever the policy domain, to accurately assess the contribution of interventions, they should be assessed for their potential to compete with existing measures. If the degree of substitutability between various interventions is found to be high, policymakers would do well to reappraise their policy mix. Our analysis complements the strand of literature that explains the motivation for recycling (e.g. Abbott et al., 2013; Berglund, 2006; Cerere et al., 2014), as well as contributing to research that explains behavioural spillovers (e.g. Bratt, 1999; Dolan and Galizzi, 2015; Truelove et al., 2014).

Using three-stage least squares (3SLS) estimation (Zellner and Theil, 1962) of a system of equations, where each of the dependent variables is also an explanatory variable in the other equations, we provide new empirical evidence for all of the UK's local governments (authorities), over the period 2004Q2 to 2013Q3. This approach accounts for any endogeneity, whereby unobserved effects are correlated with one other. ${ }^{2}$ Somewhat unique to the UK is the absence of monetary incentives directed at the household to reduce waste or to increase recycling. This allows us to undertake a more direct analysis of the trade-off between recyclables collected at the kerbside and

\footnotetext{
${ }^{1}$ D’Amato et al. (2016) state that substitutability/complementarity between waste and recycling behaviours depends on the sign of the cross partial involving recycling and waste reduction efforts but do not elaborate further. In this paper, we provide a clear link between the theoretical and empirical analysis and use the theory to explain the empirical results we obtain.

${ }^{2}$ Kinnaman and Fullerton (2000) were the first to note the importance of controlling for endogeneity within the recycling context.
} 
those materials collected from recycling centres, such as from civic amenity and bring sites, which we define as non-kerbside recycling. ${ }^{3}$

The focus of our study is on understanding the existence, or otherwise, of a trade-off between kerbside and non-kerbside provision. If households perceive kerbside to be substitutable for non-kerbside, either existing modes may be crowded out, as recycling is diverted away or, the expansion of either mode will not make a significant net contribution to the overall level of recycling. On the other hand, if households perceive them to be complementary, activities directed at the promotion of either kerbside or non-kerbside recycling will translate into a similar increase in the overall level of recycling.

While recent literature has been able to identify a positive effect arising from the introduction and expansion of a kerbside scheme (Ando and Gosslin, 2005; Jenkins et al., 2003), our analysis is sophisticated enough to account for the 'quality', as well as, the quantity of kerbside provision. Our measure of 'quality' relates to the type of container offered and its size, as well as the frequency of recycling collection. The new dataset that we use has the advantage of providing a full classification of recycling schemes of varying characteristics. Woodward et al. (2005) note the importance of providing a dedicated container as part of the kerbside scheme but do not elaborate on how differences in the characteristics of containers may elicit different responses in terms of recycling rates. Abbott et al. (2011) demonstrate that the UK dry recycling rate is sensitive to the method of collection, with wheeled storage bins, that provide the greatest opportunities for recycling, improving the recycling rate. Moreover, they show that the less frequent the residual waste collection is, the more improved will be the rate of recycling.

Section 2 outlines the policy background for the UK, section 3 presents our theoretical model and its implications, section 4 considers the empirical model and data; section 5 presents the estimation results, section 6 provides a further discussion based on the Slutsky analysis, while section 7 provides concluding remarks.

\footnotetext{
${ }^{3}$ Civic amenity sites are provided by local authorities and are facilities where households typically travel to dispose of recyclable materials. They are large-scale facilities and receive a number of materials in potentially large volumes. Bring sites are smaller scale facilities which concentrate on the collection of fewer materials e.g. paper, glass, clothing. These would be located, for example, in supermarkets or in public car parks.
} 


\section{Policy background}

A key environmental objective of the UK government is to reduce the amount of residual waste sent to landfill and to raise the quantity of recycling. UK waste policy has evolved since the publication of the Waste Strategy for England and Wales in 2000 and in response to relevant legislation from the European Union, such as the revised Waste Framework Directive (2008) and the Landfill Directive (1999/31/EC). The key features of UK waste policy are presented in Table 1. The waste hierarchy, which underpins the UK approach to waste management, adopts waste prevention, reuse and recycling, waste recovery and waste disposal in descending order of priority. The only monetary incentive applied to household waste is the landfill tax which is payable by local authorities/organisations that dispose of the waste. The recycling rewards scheme, adopted by a few authorities, rewards households/community organisations with vouchers, which are redeemable in local supermarkets. The producer responsibility regulations requires producers to recover and recycle a certain proportion of packaging. The rationale underlying these policies is that the recovery and disposal of waste imposes externalities, ranging from greenhouse gas emissions arising from landfilling waste to the potential health impacts of disposing of hazardous waste.

\section{$<$ TABLE 1 NEAR HERE $>$}

Funding for environmental services comes from two revenue streams: i) a block grant given by the central government, which funds all services; ii) local taxes levied on households and businesses. Since the taxes charged are uncorrelated with waste generation, households and businesses perceive a marginal price of zero for every unit of waste disposed beyond the first one (Callan and Thomas, 2006). At the moment, the landfill tax represents the closest attempt of the UK government to introducing market-based instruments in waste management. ${ }^{4}$ Even so, the landfill tax does not incentivise households to control their waste generation. Since the landfill tax is levied on aggregate

\footnotetext{
${ }^{4}$ The government has also introduced recycling credits in local authorities where responsibilities for waste collection and disposal are separated. The waste disposer pays the credits, equal to savings accrued from diverting waste from landfill, to the collectors to encourage recycling collections.
} 
household waste, even if householders make the link between council tax rises and the landfill tax, many households are responsible and so the free-rider effect is likely to be present.

The outcome of these efforts has been to move the UK from a position where it was recycling less than 1\% of its household waste in the 1980s to about 45\% in 2014 (DEFRA, 2015). Amongst the EU(27) it has moved from $10^{\text {th }}$ position in $2007 / 08$ to $7^{\text {th }}$ position in 2013 with its current recycling rate just pushing slightly ahead of the EU average (Abbott et al., 2011).

Nothwithstanding the major improvement in the UK's recycling performance, the recycling rate is growing at a slower rate (e.g. from 2006 to 2010 the recycling rate increased 2.2\% on average, compared to an average rise of 3.6\% from 2001 to 2005 (EEA, 2013)). In order to secure maximum gains from policy initiatives it is important to examine the potential for trade-offs between various instruments. These trade-offs should be explicitly considered when proposing a mix of instruments or introducing measures incrementally. The complexity of getting the right policy mix is highlighted by Turner et al. (1998).

Figures 1 and 2 illustrate the mix of recycling between kerbside and non-kerbside. The figures show the mean dry recycling volumes per 1,000 people, for all of the UK’s local authorities (governments) over the period 2004Q2 to 2013Q3. ${ }^{5}$ In the case of kerbside volumes (Figure 1) the average volume is 21.1 tonnes per 1,000 people but the standard deviation is 7.6 tonnes. Greater kerbside recycling intensity takes place in the Midlands and southern regions of England, where there are also greater recycling rates (Abbott et al., 2011). In the case of non-kerbside volumes, Figure 2 indicates that greater recycling effort is found in Northern Ireland, Scotland and Wales. Mean volumes are 8.7 tonnes per 1,000 people but the standard deviation is 9.9 tonnes. However, although useful these figures do not reveal the nature of the relationship between various modes of recycling. To do that we present a simple theoretical model which we then attempt to test empirically.

$<$ FIGURES 1 \& 2 NEAR HERE >

\section{A simple model}

\footnotetext{
${ }^{5}$ The term dry recyclable materials refers to waste that is free from contaminants such as construction, food or garden waste.
} 
We are interested in how the decision to recycle at the kerb interacts with non-kerbside recycling. Deriving inspiration from Beatty et al. (2007) we assume that the individual household obtains its utility from recycling its waste through various outlets. ${ }^{6}$ In addition to the time spent on recycling the household can also enjoy leisure. Thus, the household's utility function is assumed to be:

$$
U=U\left(R_{k}, R_{n k}, l\right) \text {, }
$$

where $R_{k}$ and $R_{n k}$ denote kerbside and non-kerbside volumes respectively and $l$ denotes leisure. We assume $\frac{\partial U}{\partial R_{k}}>0 ; \frac{\partial U}{\partial R_{n k}}>0 ; \frac{\partial U}{\partial l}>0$ and $U$ is concave in its three arguments. We add the assumption that it takes $\theta$ time to recycle one unit of recyclable waste at the recycling centre/bring site and $\gamma$ time to recycle one unit of recyclable waste at the kerbside. Thus, the individual household's time budget can be written as:

$$
1+\theta R_{n k}+\gamma R_{k}=T,
$$

where $T$ is total non-working time. We assume it takes longer to recycle away from the kerb so that $\theta>\gamma$. In addition to interpreting $\theta$ and $\gamma$ as time coefficients we can also think of them as shadow prices (cost of time measured at the hourly wage rate or some proportion thereof) of non-kerbside and kerbside recycling respectively. Enhanced kerbside provision increases the convenience of recycling and so reduces the amount of time taken to complete it (Viscusi et al., 2012). ${ }^{7}$ In general, anything that affects the time taken to recycle, including government intervention, can affect the value of $\theta$ and $\gamma$. Alternatively, a more complex recyclable, such as plastic takes more time, because not all plastics are recyclable and so the individual has to check its recyclability beforehand. However, for the purpose of the theoretical analysis we assume they are constant.

\footnotetext{
${ }^{6}$ As in Beatty et al. (2007) we suppose that there is a first stage optimisation where consumption choice generates an amount of waste. The second stage optimisation looks only at the utility derived from different modes of waste disposal. In particular, the individual household decides how to recycle via different channels assuming that it takes different amounts of time to recycle one unit via each channel. Fullerton and Kinnaman (1995) also assume utility is positively related to recycling quantities.

${ }^{7}$ In jurisdictions where there is a deposit-refund scheme, as in Beatty et al. (2007) and Viscusi et al. (2012), we can think of $\theta(1-s)$ as the shadow price, where the refund $s>0$ is redeemed at the civic amenity site. The existence of such a subsidy serves to reduce the shadow price differential between the two modes of recycling. However, as previously stated there are no financial incentives in the UK, so that $s=0$.
} 
From the individual's utility maximisation problem we will obtain a demand function for kerbside and non-kerbside recycling, which we denote by $R_{k}(\gamma, \theta)$ and $R_{n k}(\gamma, \theta)$ respectively. Although both quantities will also be a function of $T$ we have suppressed it, as our primary interest is only in $\gamma$ and $\theta$. However, throughout we make the reasonable assumption that both $R_{k}$ and $R_{n k}$ are normal, i.e. $\frac{\partial R_{k}}{\partial T}>0$ and $\frac{\partial R_{n k}}{\partial T}>0$.

As in standard consumer analysis, the signs of $\frac{\partial R_{n k}}{\partial \gamma}$ and $\frac{\partial R_{k}}{\partial \theta}$ will indicate the gross substitute/complement relationship between the two quantities. In particular, if $\frac{\partial R_{n k}}{\partial \gamma}>0(<0)$ then non-kerbside recycling is a gross substitute for (complement of) kerbside recycling. We can also make the analogous statement from the sign of $\frac{\partial R_{k}}{\partial \theta}$.

In terms of trying to infer the gross substitute/complement relationship between the two quantities using our database, we face the problem that shadow prices for kerbside and non-kerbside recycling cannot be observed directly. So, we cannot directly infer the signs of $\frac{\partial R_{k}}{\partial \theta}$ and $\frac{\partial R_{n k}}{\partial \gamma}$ empirically to determine the gross substitute/complement relationship. However, we can overcome this problem by using equivalent conditions for the gross substitute/complement relationship, which are derived as follows. Our assumption that both quantities are normal implies that $\frac{\partial R_{k}}{\partial \gamma}<0$ and $\frac{\partial R_{n k}}{\partial \theta}<0$. So, $R_{k}(\gamma, \theta)$ is invertible w.r.t. $\gamma$ and $R_{n k}(\gamma, \theta)$ is invertible w.r.t. $\theta$. We denote these inverse functions by $\gamma=\tilde{\gamma}\left(R_{k}, \theta\right)$ and $\theta=\tilde{\theta}\left(R_{n k}, \gamma\right)$ respectively. ${ }^{8}$ Now, by substituting $\tilde{\gamma}\left(R_{k}, \theta\right)$ for $\gamma$ into $R_{n k}(\gamma, \theta)$, we can derive the following function: $\tilde{R}_{n k}\left(R_{k}, \theta\right) \equiv R_{n k}\left(\tilde{\gamma}\left(R_{k}, \theta\right), \theta\right)$.

${ }^{8}$ Note that, $\frac{\partial \tilde{\gamma}}{\partial R_{k}}=\left(\frac{\partial R_{k}}{\partial \gamma}\right)^{-1}<0$ and $\frac{\partial \tilde{\theta}}{\partial R_{n k}}=\left(\frac{\partial R_{n k}}{\partial \theta}\right)^{-1}<0$. 
Differentiating w.r.t. $R_{k}$ we get $\frac{\partial \tilde{R}_{n k}}{\partial R_{k}}=\left(\frac{\partial R_{n k}}{\partial \gamma}\right)\left(\frac{\partial \tilde{\gamma}}{\partial R_{k}}\right)=\left(\frac{\partial R_{n k}}{\partial \gamma}\right)\left(\frac{\partial R_{k}}{\partial \gamma}\right)^{-1}$. From this, we can deduce that $\frac{\partial \tilde{R}_{n k}}{\partial R_{k}}$ and $\frac{\partial R_{n k}}{\partial \gamma}$ are of opposite signs. So, we can say that $R_{n k}$ is a gross substitute (complement) for $R_{k}$ if $\frac{\partial \tilde{R}_{n k}}{\partial R_{k}}<0(>0)$.

Similarly, we can substitute $\tilde{\theta}\left(R_{n k}, \gamma\right)$ for $\theta$ into $R_{k}(\gamma, \theta)$ and obtain the function $\tilde{R}_{k}\left(R_{n k}, \gamma\right) \equiv R_{k}\left(\gamma, \tilde{\theta}\left(R_{n k}, \gamma\right)\right)$. Using a similar reasoning as above, we can say that $R_{k}$ is a gross substitute (complement) for $R_{n k}$ if $\frac{\partial \tilde{R}_{k}}{\partial R_{n k}}<0(>0)$. Thus, in the empirical section we will try to infer the signs of $\frac{\partial \widetilde{R}_{k}}{\partial R_{n k}}$ and $\frac{\partial \tilde{R}_{n k}}{\partial R_{k}}$ to determine the gross substitute/complement relationship, which in turn may or may not be able to inform us of the substitute/complement relationship.

\section{Empirical model and data}

We investigate for all of the UK's local authorities, over the period 2004Q2 to 2013Q4, whether increasing the share of the population with access to kerbside provision improves kerbside recycling volumes and if so, is this at the expense of non-kerbside returns. ${ }^{9}$ Compared to previous contributions we consider all the dry recyclable materials collected rather than just focusing on particular types e.g. beverage containers, like for example Beatty et al. (2007). All local authorities undertake separate collections for residual waste and dry recycling materials. Recycled materials come in two forms: i) dry recycling materials (e.g. bottles, paper, card) are those waste streams that are free from contaminants, such as food, garden waste or construction materials; ii) green recycling materials, which consist of household food waste and garden waste (e.g. grass cuttings).

\footnotetext{
${ }^{9}$ Since recycling levels at the scale of the local authority are outcomes of individual decisions, it appears reasonable to assume a representative household and to infer that relationships that hold at the level of the household also hold in the aggregate on average.
} 
Given households face a choice in how to deal with their waste, there potentially could be a trade-off between kerbside recycling and non-kerbside recycling volumes. For completeness we include estimation of residual waste parameters as well. We therefore follow the approach of estimating a system of three equations, where each has explanatory variables that are dependent variables from the other two waste stream equations in the system. To estimate our system we use the Three Stage Least Squares (3SLS) estimation methodology. This allows for the joint estimation of an entire system of equations, when some of the equations contain endogenous variables, which are usually dependent variables of other variables in the system (Zellner and Theil, 1962; Davidson and Mackinnon, 1993; Greene, 2012). ${ }^{10}$ Dry kerbside recycling volumes, volumes of dry materials deposited at a recycling centre and residual waste are therefore determined as follows:

$$
\begin{aligned}
& r v_{i t}^{d k}=\alpha_{0}+\alpha_{1} r v_{i t}{ }^{d n k}+\alpha_{2} w v_{i t}+\sum_{j=1}^{9} \alpha_{3 j} m t d_{j i t}^{d k}+\sum_{j=1}^{9} \alpha_{4 j} f r_{j i t}^{d k}+\alpha_{5} n m t_{i t}+\sum_{j=1}^{5} \alpha_{6 j} X_{j i t}+\varepsilon_{i t}{ }^{d k} \\
& r v_{i t}{ }^{d n k}=\beta_{0}+\beta_{1} r v_{i t}{ }^{d k}+\beta_{2} w v_{i t}+\beta_{3} c a s_{i t}+\sum_{j=1}^{5} \beta_{4 j} X_{j i t}+\varepsilon_{i t}{ }^{d n k} \\
& w v_{i t}=\delta_{0}+\delta_{1} r v_{i t}{ }^{d k}+\delta_{2} r v_{i t}{ }^{d n k}+\sum_{j=1}^{7} \delta_{3 j} m t d_{j i t}{ }^{w v}+\sum_{j=1}^{7} \delta_{4 j} f r_{j i t}{ }^{w v}+\sum_{j=1}^{5} \delta_{5 j} X_{j i t}+\varepsilon_{i t}{ }^{w v},
\end{aligned}
$$

where $r v_{i t}^{d k}$ is the log volume of dry recycling materials collected at the kerbside, $r v_{i t}^{d n k}$ is the log volume of dry recycling materials deposited at recycling centres (both civic amenity and bring sites) and $w v_{i t}$ is the log volume of residual waste collected from households. In each equation, the dependent variable is explained by factors directly related to the waste stream, such as aspects of service provision. For example, in the case of kerbside recycling and residual waste collection these consist of methods of collection and frequency of collection. Additionally in the case of kerbside, the

\footnotetext{
10 3SLS uses an instrumental variable approach that produces consistent estimates, which control for the cross-correlation in the error terms across equations, whilst also avoiding any estimation bias coming from OLS when the disturbances and endogenous explanatory variables are correlated. 3SLS estimates are also expected to be more efficient than estimates from Two Stage Least Squares (2SLS) when the estimated residuals are normally distributed. 3SLS estimates have the same asymptotic distribution as Full Information Maximum Likelihood (FIML) estimates, though if the error term is correlated with at least one independent variable, the 3SLS will be biased in small samples.
} 
number of materials collected is relevant whereas, in the case of non-kerbside, aspects of collection are not relevant but number of recycling centres are. In addition to these direct effects, there are also indirect effects arising from alternative modes of recycling and disposal.

In the first equation, the methods of dry recycling collection are given by $m t d d_{j i t}^{d k}$, which denotes the percentage of the population with access to the $\mathrm{j}^{\text {th }}$ method of dry recycling collection in local authority i at time period t. There are nine methods of collection categorised, which vary according to the size of the container used for collection, therefore providing varying amounts of recycling capacity (see Appendix: Data and Sources). For each method of collection, there is a frequency of dry recycling collection $f r_{j i t}^{d k}$, which denotes the $j^{\text {th }}$ frequency of collection offered by local authority $i$ at period t. The frequency of dry collection is categorised as being either more frequent than weekly, weekly, fortnightly or less frequent than fortnightly. We use a scale where increasing values imply lower frequencies of collection. The number of materials collected at the kerbside is denoted by $n m t_{i t}$, while $X_{j i t}$ refers to a series of control variables that could explain the variation in recycling performance through the size of the local authority and its composition. These are consistent with the variables commonly used in the literature, namely the log of population; the log of the local authority's land area; the log of population density; the log of the local authority's index of deprivation; and the log of urban population. A more urbanised population tends to be associated with greater provision of kerbside recycling (Viscusi et al., 2012). Higher population densities capture a higher prevalence of multi-dwelling occupancy, which tends to imply lower kerbside recycling yields (Abbott et al., 2013). Lower kerbside yields have also been associated with higher levels of deprivation (WRAP, 2010b).

In the second equation $\operatorname{cas}_{i t}$ refers to the number of recycling centres where materials can be deposited. For the determinants of residual waste, all independent variables are as previously defined, except for $m t d{ }_{j i t}{ }^{w v}$ and $f r_{j i t}{ }^{w v}$, which are methods of residual waste collection and their frequencies. There are seven methods of residual waste collection and $m t d_{j i t}{ }^{w v}$ denotes the proportion of the 
population with access to the jth method of residual waste collection offered by local authority i at period t.

Taking the first two equations in (3) we empirically model the relationship between kerbside and non-kerbside recycling through their quantities. Using the equivalent conditions we derived in the previous section, we can deduce the gross complement/substitution relationship from the signs of $\alpha_{1}$ and $\beta_{1}$ which capture $\frac{\partial \widetilde{R}_{k}}{\partial R_{n k}}$ and $\frac{\partial \widetilde{R}_{n k}}{\partial R_{k}}$ respectively. In particular, if $\beta_{1}<0$ then non-kerbside is a gross substitute for kerbside. However if $\beta_{1}>0$ then we can say that non-kerbside is a gross complement of kerbside.We can also make an analogous inference about whether kerbside is a gross substitute or complement for non-kerbside from the sign of $\alpha_{1}$.

We would expect that increasing the size of the container, frequency of collection and number of materials would reduce the shadow price of kerbside, which in turn increases kerbside volumes. Similarly we would expect that increasing the number of civic amenity sites would reduce the shadow price of non-kerbside resulting in an increase in its volume.

We also produce separate estimates for green recycling, hitherto not considered by the literature, which have a different set of determinants. We estimate the following system:

$$
\begin{aligned}
& r v_{i t}{ }^{g k}=\phi_{0}+\phi_{1} r v_{i t}{ }^{g n k}+\phi_{2} w v_{i t}+\sum_{j=1}^{4} \phi_{3 j} m t d_{j i t}^{g k}+\sum_{j=1}^{4} \phi_{4 j} f r_{i t}{ }^{g k}+\sum_{j=1}^{5} \phi_{5 j} X_{j i t}+\varepsilon_{i t}{ }^{g k} \\
& r v_{i t}^{g n k}=\varphi_{0}+\varphi_{1} r v_{i t}{ }^{g k}+\varphi_{2} w v_{i t}+\varphi_{3} c a s_{i t}+\sum_{j=1}^{5} \varphi_{4 j} X_{j i t}+\varepsilon_{i t}{ }^{g n k} \\
& w v_{i t}=\tau_{0}+\tau_{1} r v_{i t}{ }^{g k}+\tau_{2} r v_{i t}{ }^{g n k}+\sum_{j=1}^{7} \tau_{3 j} m t d_{j i t}{ }^{w v}+\sum_{j=1}^{7} \tau_{4 j} f r_{i t}{ }^{w v}+\sum_{j=1}^{5} \tau_{5 j} X_{j i t}+\varepsilon_{i t}{ }^{w v}
\end{aligned}
$$

where $r v_{i t}{ }^{g k}$ is the volume of green waste that is recycled at the kerbside, $r v_{i t}{ }^{g n k}$ denotes the green waste recycled at civic amenity sites, and $w v_{i t}$ again is the volume of residual waste collected from households. The four methods of green recycling collection are denoted by $m t^{g k}$, showing the proportion of the local authority's population with access to green recycling collection method $\mathrm{j}$ in 
local authority i at time period t. The respective frequencies of collection are given by $f r_{j i t}^{g k}$. All other variables included are the same as those in the dry recycling system. The coefficients follow similar interpretations to those included in the dry recycling system of equations (3). Specifically, following on from the previous analysis $\varphi_{1}$ captures $\frac{\partial \tilde{R}_{n k}}{\partial R_{k}}$ so that if $\varphi_{1}<0$, we can deduce that non-kerbside green waste is a gross substitute for kerbside green waste collections. ${ }^{11}$ If $\varphi_{1}>0$, non-kerbside is a gross complement of kerbside.

The recycling and residual waste data, as well as the determinants, come from the online portal http://www.wastedataflow.org/ to which local authorities submit recycling and waste data. One of the main advantages of using this source is that the series are reported consistently in response to a questionnaire completed by all UK local authorities. We utilize separate series for recycling at the kerbside and non-kerbside, where the latter is defined as the sum of recycling at civic amenity and bring sites. The socio-economic series for the control variables comes from the Office of National Statistics. Data from these two sources were combined to produce a comprehensive database on local authorities. ${ }^{12}$ We utilise data for all of the UK’s local authorities over the period 2004Q2 to 2013Q3, the longest time period for which data is available. A full list of the variables used for estimation and their data sources are provided in the Appendix.

\section{Estimation results}

The 3SLS estimation results of our system of equations in (3) are shown in Table 2. The research question we seek to address is whether there is trade-off between the two modes of recycling when there is change in the provision of one of them. We have shown in section 4 that to answer this question we can examine the sign of the derivative $\frac{\partial \widetilde{\boldsymbol{R}}_{n k}}{\partial \boldsymbol{R}_{k}}$. From Panel (B) the variable $r v_{i t}^{d k}$ is

\footnotetext{
${ }^{11}$ In the green context $R_{n k}$ refers to green waste that is recycled at the civic amenity site and $\gamma$ is the shadow price of recycling green waste at the kerb.

${ }^{12}$ This dataset which formed one of the outputs from ESRC project 'Examining variation in recycling across UK' (RES-000-22-3738) is available from the UK ESDS archive.
} 
statistically insignificant. ${ }^{13}$ So, even if improved kerbside recycling provision raises kerbside recycling volumes, this is not at the expense of returns to recycling centres.

Our analysis also allows us to examine whether expanding the role of non-kerbside recycling facilities affects kerbside provision. We can see in Panel (A) that the statistically significant $r v_{i t}{ }^{d n k}$ variable with a negatively signed estimated coefficient implies that as recycling volumes collected from recycling centres increase, volumes recovered at the kerbside are reduced.

We also include the results for methods, frequencies and number of materials collected at the kerbside. In general, the results conform to expectations. As these aspects of recycling collections improve, the shadow price of kerbside collections falls to reflect this and the consequences of this is that kerbside volumes increase. In the case of non-kerbside volumes, increasing the number of recycling centres has a positive effect through reducing the cost of recycling via this channel. In both of the estimated equations, the results of the $w v_{i t}$ variable indicate that greater volumes of residual waste will lower both kerbside and non-kerbside recycling volumes, albeit with a smaller marginal effect for non-kerbside than for kerbside recycling. The result can probably be explained by the fact that residual waste is collected directly from households like kerbside recycling materials, so has a more direct effect on kerbside recycling. ${ }^{14}$ The level of the population is also positively related to non-kerbside volumes.

The estimation results for the control variables conform to expectations and are consistent across both panels. More urbanised populations lead to greater recycling volumes at the kerb. However, larger and more densely populated areas work in the opposite direction. It may be that the larger the area, the lower the opportunities for recycling as recycling provision may be low or absent. However, without knowing more about the specific characteristics of a particular area, it is difficult to draw firm conclusions from this. Deprivation is not significant in the kerbside recycling equation. However, deprivation is largely determined by social grade, which relates to occupation, and in turn is

\footnotetext{
${ }^{13}$ Albeit that the coefficient $\beta_{1}$, which represents $\frac{\partial \widetilde{R}_{n k}}{\partial R_{k}}$, is positive

${ }^{14}$ We are grateful to an anonymous referee for highlighting this beneficial effect of kerbside recycling.
} 
highly correlated to income and this has been found to be ambiguously related to recycling behaviour (Abbott et al., 2011; Viscusi et al., 2012). ${ }^{15}$

Bringing our theoretical and empirical results together we can conclude that decreasing (increasing) the shadow price of kerbside does not decrease (increase) non-kerbside recycling. On the other hand, decreasing (increasing) the shadow price of non-kerbside recycling does decrease (increase) kerbside recycling. Thus, we can infer that kerbside recycling is a gross substitute for non-kerbside recycling but not the other way around. Although at first glance this appears odd, we know from standard analysis that this is possible because the gross substitute/complement relationship between two quantities does not have to be symmetric.

\section{$<$ TABLE 2 NEAR HERE >}

Table 3 presents the results from estimating the system of equations in (4) that explain the recycling of green waste volumes and residual waste. Looking at panel (A) and panel (B) together we see that the coefficients for the collection of non-kerbside green waste $\left(r v_{i t}^{g n k}\right)$ and green waste collected at the kerbside $\left(r v_{i t}^{g k}\right)$ are both negatively signed and statistically significant. Thus, unlike in the case of dry recycling, these two modes of green waste recycling are gross substitutes for each other. In particular, as the provision of kerbside green waste collections improves we can expect to see a reduction in non-kerbside returns.

\section{$<$ TABLE 3 NEAR HERE $>$}

The frequency of collection appears to be less important for green waste than for dry materials. Only the index of deprivation and the size of the urban population are found to be statistically significant amongst the control variables. More deprived local authorities produce lower green recycling volumes, a result which might be explained by the fact that deprived areas tend to be more urbanised and they are likely to have smaller green space. The overall fit of the 3SLS equations appears to be lower for the green waste recycling equation than when explaining dry recycling materials, with an $\mathrm{R}^{2}$ of -0.077 even found for the non-kerbside green recycling equation. This latter

\footnotetext{
${ }^{15}$ Alternatively, higher incomes can be associated with higher opportunity costs of time and hence lower recycling. Higher incomes imply greater demand for environmental quality and so more recycling.
} 
measure of goodness of fit implies our equation predicts the volume of green recycling materials from recycling centres worse than a constant only model (STATA, 2015). From the residual waste equation in panel (C) we can see that the more waste that is recycled at the kerb rather than at the recycling centre, the greater the diversion of waste from landfill.

\section{Further discussion}

So far we have only considered the gross relationship between kerbside and non-kerbside. However, we could also consider the substitute/complement relationship using the Slutsky analysis adapted to our particular context, which is conceptually more sound than the gross relationship. ${ }^{16}$ Of course it is well known that because of issues of unobservability it is not possible to make direct inference of the substitute/complement relationship from empirical analysis. However, it may be possible to make indirect inference about this relationship by using the empirical results about the gross relationship. Therefore, we will briefly consider the Slutsky equations for our context to see if we can deduce the substitute/complement relationship between kerbside and non-kerbside based on our empirical findings of the gross relationship.

The Slutsky equations for our model given in section 4 are:

$$
\begin{gathered}
\frac{\partial R_{n k}{ }^{h}}{\partial \gamma}=\frac{\partial R_{n k}}{\partial \gamma}+\frac{\partial R_{n k}}{\partial T} R_{k} \\
\frac{\partial R_{k}{ }^{h}}{\partial \theta}=\frac{\partial R_{k}}{\partial \theta}+\frac{\partial R_{k}}{\partial T} R_{n k},
\end{gathered}
$$

where $\frac{\partial R_{n k}{ }^{h}}{\partial \gamma}$ and $\frac{\partial R_{k}{ }^{h}}{\partial \theta}$ denote the Hicksian substitution effects, whose signs will determine the substitute/complement relationship. ${ }^{17}$ It may be mentioned that, unlike the gross relationship, the substitute/complement relationship is symmetric so it is sufficient to look at only one of the two

\footnotetext{
${ }^{16}$ In distinguishing the substitute/complement relationship from the gross substitute/complement relationship we are following terminology as in Mas-Colell et al. (1995).

${ }^{17} \frac{\partial R_{n k}}{\partial T} R_{k}$ and $\frac{\partial R_{k}}{\partial T} R_{n k}$ denote the income effects.
} 
Hicksian substitution effects. Therefore without loss of generality, we will look at the sign of $\frac{\partial R_{n k}{ }^{h}}{\partial \gamma}$ for the relationship between kerbside and non-kerbside recycling.

For completeness, we will first derive a fairly intuitive condition for the substitute/complement relationship from a theoretical perspective. Substituting (2) into (1) in the individual's utility maximisation problem given in section 4 , we can define a function ${ }^{18}$

$$
V\left(R_{k}, R_{n k}, T\right) \equiv U\left(R_{k}, R_{n k}, T-\theta R_{n k}-\gamma R_{k}\right)
$$

Denoting the second derivative of $V$ w.r.t. $k$ and $n k$ as $V_{k n k}$ we get:

$$
V_{k n k}=U_{k n k}-\theta U_{k l}-\gamma U_{n k l}+\gamma \theta U_{l l}
$$

We show in a supplementary appendix (available from the authors upon request) that whether $\frac{\partial R_{n k}{ }^{h}}{\partial \gamma}$

$\gtrless 0$ depends on whether $V_{k n k} \lessgtr 0$. For example, $V_{k n k}>0$ implies that $\frac{\partial R_{n k}{ }^{h}}{\partial \gamma}<0$, that is kerbside and non-kerbside recycling are complements of each other, which intuitively makes sense as their marginal utilities move together. On the other hand, $V_{k n k}<0$ implies that $\frac{\partial R_{n k}{ }^{h}}{\partial \gamma}>0$, that is the two modes of recycling are substitutes for each other.

Using the inference we have drawn about the gross relationships from our estimation results and the Slutsky equations we will now examine whether we can make any indirect inference from our dataset about the substitute/complement relationship. Let us first look at the case of dry recycling. There we could not say that non-kerbside was a gross substitute for kerbside. This finding together with (5) does not allow us to say whether the two modes of recycling are substitutes or complements of each other. ${ }^{19}$ On the other hand, we also found that kerbside was a gross substitute for non-

\footnotetext{
${ }^{18}$ Since we assume concavity of $U$ it also follows that $V$ is concave in $R_{k}$ and $R_{n k}$ for any $T$.

${ }^{19}$ When $\frac{\partial R_{n k}}{\partial \gamma}$ is negative, equation (5) does not allow us to infer the sign of $\frac{\partial R_{n k}{ }^{h}}{\partial \gamma}$.
} 
kerbside, which together with (6) allow us to infer that the two modes of recycling are substitutes for each other. ${ }^{20}$

In the case of green recycling, we found that kerbside and non-kerbside were gross substitutes for each other. So by using either (5) or (6) we can infer that both Hicksian substitution effects are positive. Thus, either of the two inferences drawn regarding the gross relationship yields the same conclusion, namely, the two modes of green recycling are substitutes for each other.

It is interesting to note the contrast between the dry recycling and green recycling. In the case of dry recycling, the empirical findings alone suggest no trade-off when considering a change in the shadow price of kerbside, but a trade-off when considering a change in the shadow price of nonkerbside. However, combining the empirical findings with the theory suggests that there is a trade-off irrespective of whether we consider a change in either shadow price. In the case of green recycling whether we consider the empirical findings on their own or in combination with theory, we obtain the unambiguous conclusion that there is a trade-off.

\section{Conclusion}

A primary environmental objective of most governments is to grow the amount of household waste that is recycled rather than sent to landfill or incineration. In achieving this goal, each government needs to choose how it wants to collect waste in order to maximize the recycling rate. It has been common to rely on kerbside recycling collections, given that they are expected to make the process of recycling waste more convenient, therefore reducing the amount of leisure activity devoted to the activity. But kerbside recycling could partially displace recycling made away from the kerb at recycling centres. Our theoretical model has shown that policymakers need to reflect on whether their chosen approach to waste recycling collection affects the values of $\theta$ and $\gamma$, the coefficients which measure the time incurred in non-kerbside and kerbside recycling. If there is no discernible impact on the time coefficients, then policymakers need not worry about the potential for trade-off between the

${ }^{20}$ When $\frac{\partial R_{k}}{\partial \theta}$ is positive, equation (6) allows us to infer that $\frac{\partial R_{k}{ }^{h}}{\partial \theta}$ is positive. 
two modes of recycling. However, if a government intervention affects the time taken to perform an activity the obvious question to ask is whether the level of that activity is affected. Our analysis points out that it is also important to assess how the levels of associated activities are affected, as this will also enhance or detract from the effectiveness of the initial intervention on the overall policy objective of increasing recycling volumes.

We focus on the potential trade-off between kerbside recycling volumes and non-kerbside volumes, for the UK's local authorities from 2004Q2 to 2013Q3 but the message of our analysis has broader applications. In general, policymakers should consider interactions between the activity targeted by the intervention and other related activities to assess the net benefits in achieving the objective. In our particular study, we distinguished between dry and green recycling and looked at the trade-off between kerbside and non-kerbside recycling in each case as a result of a change in the provision of kerbside or non-kerbside facilities. Our empirical findings for dry recycling suggested no trade-off between the two modes of recycling for a change in the provision of kerbside provision but the existence of a trade-off for a change in non-kerbside provision. For green recycling, our empirical findings suggested an unambiguous trade-off irrespective of the change in provision we consider.

We were also interested in exploring whether it was possible to draw inferences about the more conceptually sound notion of a substitute/complement relationship, as opposed to the gross relationship. However, as this could not be done directly by looking at the empirical findings we had to use a line of reasoning that brought together the empirical findings with Slutsky analysis applied to our context. In doing so, we could infer that kerbside and non-kerbside recycling were substitutes for one another, both for dry and green recycling. In other words, there is a trade-off between the two modes of recycling (both dry and green), irrespective of the change in provision considered. Thus, our study shows that it is possible to arrive at different conclusions about the trade-off, depending on whether we rely only on the empirical findings or combine it with theory. This has implications for policy interventions. In particular, in the case of dry recycling, if one relies on the empirical findings alone, then possible trade-offs is not a cause for concern when considering interventions to kerbside provision, but is a cause for concern when considering interventions to non-kerbside provision. However, if one relies on the empirical findings along with the theory, then possible trade-offs are not 
a cause for concern whether we consider interventions to either mode of recycling provision.

Fortunately, in the case of green recycling, the distinction between relying only on empirical findings or combining them with theory does not arise, since in both cases possible trade-offs is a cause for concern.

Compared to previous studies, (Beatty et al., 2007; D’Amato et al., 2016; Jenkins et al., 2003; Sidique et al., 2010a,b; Viscusi et al., 2012) we find evidence of a negative interaction between different modes of recycling. We go further by making the distinction between whether services are substitutes/complements or gross substitutes/complements and show that this might matter for policy interventions.

Another interesting point that emerged from our analysis is that it appears that an increase in kerbside recycling can reduce residual waste whereas an increase in non-kerbside does not. This is noteworthy in the light of the waste hierarchy, where the first priority is waste prevention

Further research could consider whether this result holds across the various materials that constitute our measure of dry recycling materials e.g. separate estimates for glass versus plastics. Moreover, given the variation in recycling performance across the UK, shown in Figures 1 and 2, a comprehensive regional analysis could identify whether our results hold across the regions and if trade-offs exist in some areas, allowing recycling practice to be focused more clearly to maximise recycling objectives.

\section{Acknowledgements}

We are grateful to the Economic Social Research Council [grant no. RES-000-22-3738] which provided funding for the initial data collection (2011). Grateful thanks are also due to Liam Collins and Sita Devi Patel for research assistance in extending the dataset. Shasikanta Nandeibam and Lucy O'Shea were also supported through funding from the European Union Seventh Framework Programme (FP7/2007-2013) under grant agreement n 613420. 


\section{References}

Abbott, A., Nandeibam, S., O’Shea, L., 2011. Explaining the variation in recycling rates across the UK. Ecological Economics 70, 2214-2223.

Abbott, A., Nandeibam, S., O’Shea, L., 2013. Recycling: social norms and warm-glow revisited. Ecological Economics 90, 10-18.

Ando, A.W., Gosselin, A.Y., 2005. Recycling in multifamily dwellings: does convenience matter? Economic Inquiry 43, 426-438.

Beatty T. K. M., Berck, P., Shimshack, J. P., 2007. Curbside recycling in the presence of alternatives. Economic Inquiry 45, 739-755.

Bel, G., Gradus, R., 2016. Effects of unit based pricing on household waste collection demand: a meta-regression analysis. Resource and Energy Economics 44, 169-182.

Berglund, C., 2006. The assessment of households' recycling costs: the role of personal motives. Ecological Economics 56, 560-569.

Bratt, C., 1999. Consumers' environmental behaviour generalised: sector-based or compensatory? Environment and Behaviour 31, 28-44.

Callan, S. J., Thomas, J. M., 1997. The impact of state and local policies on the recycling effort. Eastern Economic Journal 23, 411-423.

Callan, S. J., Thomas, J. M., 2006. Analyzing demand for disposal and recycling services: a systems approach. Easter Economic Journal 32, 221-240.

Cerere G., Mancinelli, S., Mazzanti, M., 2014. Waste prevention and social preferences: the role of intrinsic and extrinsic motivations. Ecological Economics 107, 163-176.

Council Directive, 1999. On the landfill of waste. Official Journal of the European Communities, Council Directive 99/31/EC.

Dahlén, L., Vukicevic, S., Miejer, J., Lagerkvist, A., 2007. Comparison of different collection systems for sorted household waste in Sweden. Waste Management 27, 1298-1305.

D’Amato A., Mancinelli, S., Zoli, M., 2016. Complementarity vs substitutability in waste management behaviours. Ecological Economics 123, 84-94. 
Davidson, R., Mackinnon, J., 1993. Estimation and inference in Econometrics. New York: Oxford University Press.

DEFRA, 2016. Billions fewer plastic bags on the streets. Access online at https://www.gov.uk/government/news/billions-fewer-plastic-bags-on-the-streets

Department for Communities and Local Government, 2014. Guidance on weekly rubbish collections: delivering a frequent and comprehensive service. Access online at https://www.gov.uk/government/uploads/system/uploads/attachment data/file/271435/BinBible -2-NT3.pdf

Department for Environment Food \& Rural Affairs, 2015. UK statistics on waste. Access online at https://www.gov.uk/government/uploads/system/uploads/attachment_data/file/487916/UK_Stat istics on Waste statistical notice $1512 \quad 2015$ update f2.pdf

Dolan, P., Galizzi, M. M., 2015. Like ripples on a pond: behavioural spillovers and their implications for research and policy. Journal of Economic Psychology 47, 1-16.

EEA, 2013. Managing municipal waste - a review of achievements in 32 European countries. European Environment Agency Report No 2 accessed on 12/4/2013 at http://www.eea.europa.eu/publications/managing-municipal-solid-waste.

European Union, 2008. Directive 2008/98/EC of the European Parliament and the Council of 19 November 2008 on Waste and Repealing Certain Directives. Official Journal of the European Union, 22/11/2008.

Fullerton, D., Kinnaman, T. C., 1995. Garbage, recycling and illicit burning or dumping. Journal of Environmental Economics and Management 29, 78-91.

Greene, W., 2012. Econometric Analysis. $7^{\text {th }}$ edition. Upper Saddle River, NJ: Prentice Hall.

Jenkins, R., Martinez, S., Palmer, K., Podolsky, M., 2003. The determinants of household recycling: a material specific analysis of recycling program features and unit pricing. Journal of Environmental Economics and Management 45, 294-318.

Kinnaman, T. C., Fullerton, D., 2000. Garbage and recycling with endogenous local policy. Journal of Urban Economics 48, 419-42. 
Larsen, A., Merrild, H., Møller, J., Christensen, T., 2010. Waste collection systems for recyclables: an environmental and economic assessment for the municipality of Aarhus (Denmark). Waste Management 30, 744-754.

Mas-Colell, A., Whinston, M. D., Green, J., 1995. Microeconomic Theory. Oxford University Press, New York.

Merritt, A.C., Effron, D.A., Monin, B., 2010. Moral self-licensing: when being good frees us to be bad. Social and Personality Compass 4/5, 344-357.

Sidique, S., Joshi, S., Lupi, F., 2010a. Factors influencing the rate of recycling: an analysis of Minnesota counties. Resources, Conservation and Recycling 54, 242-249.

Sidique, S., Lupi, F., Joshi, S., 2010b. The effects of behaviour and attitudes on drop-off recycling activities. Resources, Conservation and Recycling 54, 163-170.

StataCorp. 2015. Stata 14 Base Reference Manual. College Station, TX: Stata Press.

Turner R.K. Salmons, R., Powell, J. and Craighill, A., 1998. Green taxes, waste management and political economy. Journal of Environmental Management 53, 121-136.

Truelove, H., Carrico, A., Weber, E., Raimi, K., Vanderbergh, M., 2014. Positive and negative spillover of environmental behaviour: an integrative review and theoretical framework. Global Environmental Change 29, 127-138.

Vaughan, R. (pers. comm.) Head of Recycling, Resources, Resource, Atmosphere and Sustainability (RAS), Department for Environment, Food and Rural Affairs, UK.

Viscusi, W., Huber, J., Bell, J., 2012. Alternative policies to increase recycling of plastic water bottles in the United States. Review of Environmental Economics and Policy 6, 190-211.

Woodward, R., Bench, M., Harder, M., 2005. The development of a UK kerbside scheme using known practice. Journal of Environmental Management, 75, 115-127.

WRAP, 2009. Analysis of kerbside dry recycling performance in England 2007/8. Waste Resources Action Programme.

WRAP, 2010a. Environmental benefits of recycling - 2010 update. Waste and Resources Action Programme, Final report, available at http://www.wrap.org.uk/wrap_corporate/publications/benefitsrecycling.html 
WRAP, 2010b. Analysis of kerbside dry recycling performance in the UK 2008/9. Waste Resources Action Programme.

WYG Environment, 2012. Review of kerbside recycling collection schemes in the UK in 2010/11.

Zellner, A., Theil, H., 1962. Three stage least squares: simultaneous estimate of simultaneous equations. Econometrica 29, 54-79 


\section{Appendix: Data and Sources}

Variable Definition

Dependent variables

$r v_{i t}^{d k} \quad$ Log of tonnes of dry recycled materials collected through kerbside collection schemes

$r v_{i t}^{d n k} \quad$ Log of tonnes of dry recycled materials collected through deposits to either civic amenity sites or bring sites

$r v_{i t}^{g k} \quad$ Log of tonnes of green recycled materials collected through kerbside collection schemes

$r v_{i t}^{g n k} \quad$ Log of tonnes of green recycled materials collected through deposits to either civic amenity sites or bring sites

$w v_{i t}$

Log of tonnes of residual waste collected through kerbside collection

Methods of dry recycling waste collection

$m t d_{1 i t}^{d k} \quad$ Proportion of the population with access to 'Kerbside box $<35$ litres' method

$m t d_{2 i t}^{d k} \quad$ Proportion of the population with access to 'Kerbside box 35-50 litres' method

$m t d_{3 i t}^{d k} \quad$ Proportion of the population with access to 'Kerbside box $>50$ litres' method

$m t d_{4 i t}^{d k} \quad$ Proportion of the population with access to 'Reusable sacks' method

$m t d_{5 i t}^{d k} \quad$ Proportion of the population with access to 'Non-reusable sacks' method

$m t_{6 i t}^{d k} \quad$ Proportion of the population with access to 'Wheeled bin<120 litres' method

$m t d_{7 i t}^{d k} \quad$ Proportion of the population with access to 'Wheeled bin 120-180 litres' method

$m t d_{8 i t}^{d k} \quad$ Proportion of the population with access to 'Wheeled bin 181-240 litres' method

$m t d_{9 i t}^{d k} \quad$ Proportion of the population with access to 'Wheeled bin>241 litres' method

Frequencies of dry recycling waste collection

$\mathrm{fr}_{\text {lit }}^{\mathrm{dk}} \quad$ Collection frequency for 'Kerbside box $<35$ litres' method

$f r_{2 i t}^{d k} \quad$ Collection frequency for 'Kerbside box 35-50 litres' method

$\mathrm{fr}_{3 i t}^{\mathrm{dk}} \quad$ Collection frequency for 'Kerbside box $>50$ litres' method

$\mathrm{fr}_{4 \mathrm{it}}^{\mathrm{dk}} \quad$ Collection frequency for 'Reusable sacks' method

$\mathrm{fr}_{5 \mathrm{it}}^{\mathrm{dk}} \quad$ Collection frequency for 'Non-reusable sacks' method

$\mathrm{fr}_{6 \mathrm{it}}^{\mathrm{dk}} \quad$ Collection frequency for 'Wheeled bin $<120$ litres' method

$\mathrm{fr}_{7 \mathrm{it}}^{\mathrm{dk}} \quad$ Collection frequency for 'Wheeled bin 120-180 litres' method

$\mathrm{fr}_{8 \mathrm{di}}^{\mathrm{dk}} \quad$ Collection frequency for 'Wheeled bin 181-240 litres' method

$f r_{9 i t}^{d k} \quad$ Collection frequency for 'Wheeled bin>241 litres' method

Methods of green recycling waste collection

$m t d_{1 i t}^{g k} \quad$ Proportion of the population with access to 'Reusable sacks' method 
$m t_{2 i t}^{g k} \quad$ Proportion of the population with access to 'Wheeled bin $<120$ litres' method

$m t d_{3 i t}^{g k} \quad$ Proportion of the population with access to 'Wheeled bin 120-180 litres' method

$m t_{4 i t}^{g k} \quad$ Proportion of the population with access to 'Wheeled bin 241+ litres' method

Frequencies of green recycling collection

$f r_{1 i t}^{g k} \quad$ Collection frequency for 'Reusable sacks' method

$\mathrm{fr}_{2 \mathrm{it}}^{\mathrm{gk}} \quad$ Collection frequency for 'Wheeled bin $<120$ litres' method

$\mathrm{fr}_{3 i t}^{g k} \quad$ Collection frequency for 'Wheeled bin 120-180 litres' method

$\mathrm{fr}_{4 i t}^{g k} \quad$ Collection frequency for 'Wheeled bin 241+ litres’ method

Methods of residual waste collection

$m t d_{1 i t}^{w v} \quad$ Proportion of the population with access to 'Wheeled Bin 100-150 litres' method

$m t d_{2 i t}^{w v} \quad$ Proportion of the population with access to 'Wheeled Bin 151-200 litres' method

$\operatorname{mtd}_{3 i t}^{w v} \quad$ Proportion of the population with access to 'Wheeled Bin 251-300 litres' method

$\operatorname{mtd}_{4 i t}^{w v} \quad$ Proportion of the population with access to 'Wheeled Bin>350 litres' method

$m t d_{5 i t}^{w v} \quad$ Proportion of the population with access to 'Plastic sacks' method

$\operatorname{mtd}_{6 i t}^{w v} \quad$ Proportion of the population with access to 'Household refuse bins' method

$m t d_{7 i t}^{w v} \quad$ Proportion of the population with access to 'Communal bins' method

Frequencies of residual waste collection

$\mathrm{fr}_{1 i \mathrm{w}}^{\mathrm{wV}} \quad$ Collection frequency for 'Wheeled Bin 100-150 litres' method

$\mathrm{fr}_{2 i t}^{\mathrm{wv}} \quad$ Collection frequency for 'Wheeled Bin 151-200 litres' method

$\mathrm{fr}_{3 \mathrm{it}}^{\mathrm{wv}} \quad$ Collection frequency for 'Wheeled Bin 251-300 litres' method

$\mathrm{fr}_{4 i t}^{w v} \quad$ Collection frequency for 'Wheeled Bin>350 litres' method

$\mathrm{fr}_{5 i t}^{\mathrm{wv}} \quad$ Collection frequency for 'Plastic sacks' method

$\mathrm{fr}_{6 \mathrm{it}}^{\mathrm{wv}} \quad$ Collection frequency for 'Household refuse bins' method

$\mathrm{fr}_{7 \mathrm{it}}^{\mathrm{wv}} \quad$ Collection frequency for 'Communal bins' method

Additional recycling determinants

$n m t_{i t} \quad$ Number of dry recycling materials collected at kerbside

cas $_{\text {it }} \quad$ Log of number of civic amenity sites in the local authority

Control variables

$\begin{array}{ll}X_{1 i t} & \log \text { of the local authority population } \\ X_{2 i t} & \log \text { of the local authority's area in hectares }\end{array}$ 


$\begin{array}{ll}X_{3 i t} & \log \text { of population density } \\ X_{4 i t} & \log \text { of the local authority's index of deprivation } \\ X_{5 i t} & \log \text { of urban population }\end{array}$

Notes: the source for the control variables is http://www.ons.gov.uk, while all other series come from http://www.wastedataflow.org/ 
Figure 1: Kerbside dry recycling volumes per 1,000 people (all materials), average values 2004Q2 to 2013Q3.

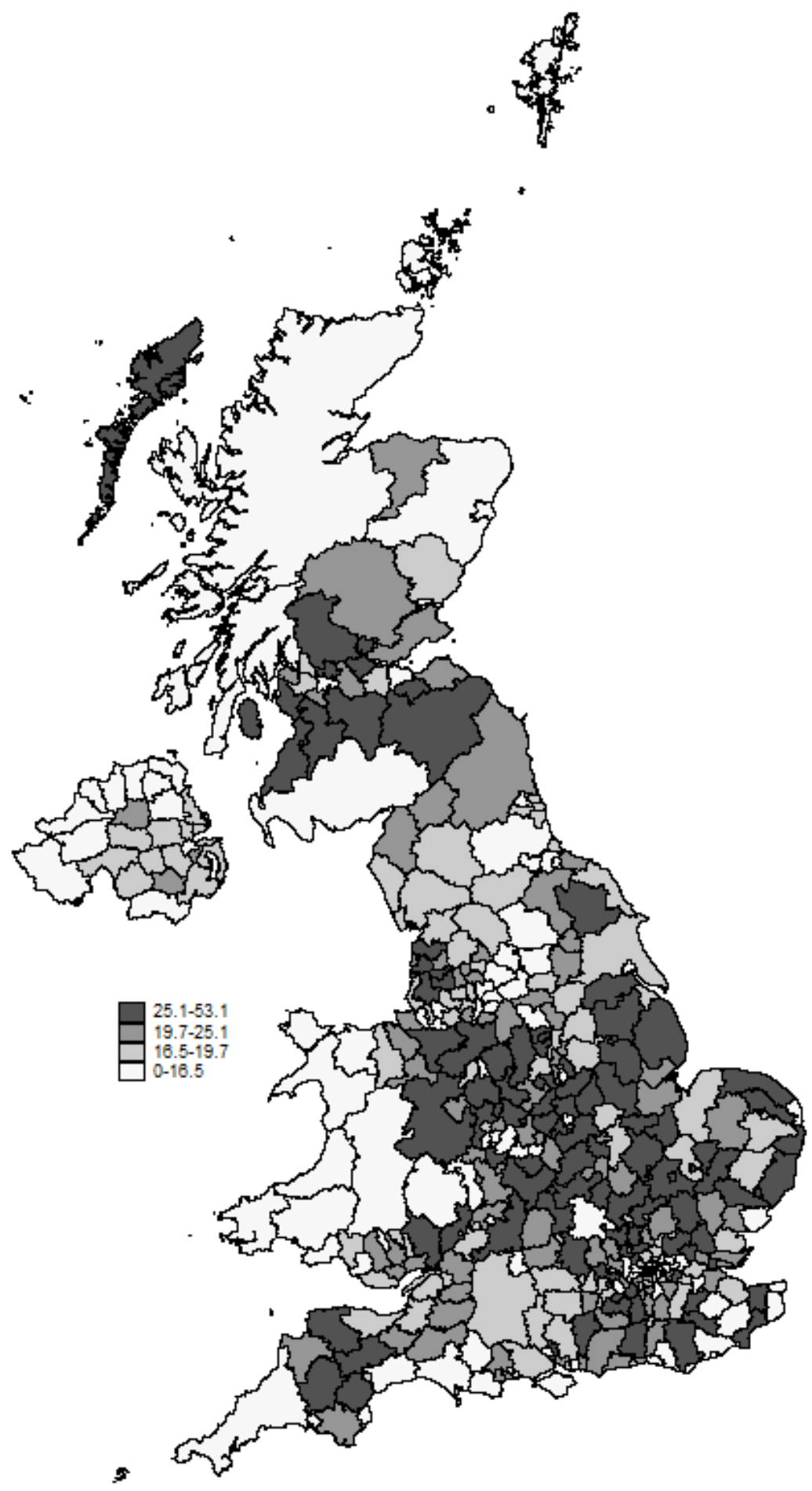

Notes: Produced using the spmap command of STATA with data taken from http://www.wastedataflow.org. 
Figure 2: Non-kerbside dry recycling volumes per 1,000 people (all materials), average values 2004Q2 to 2013Q3.

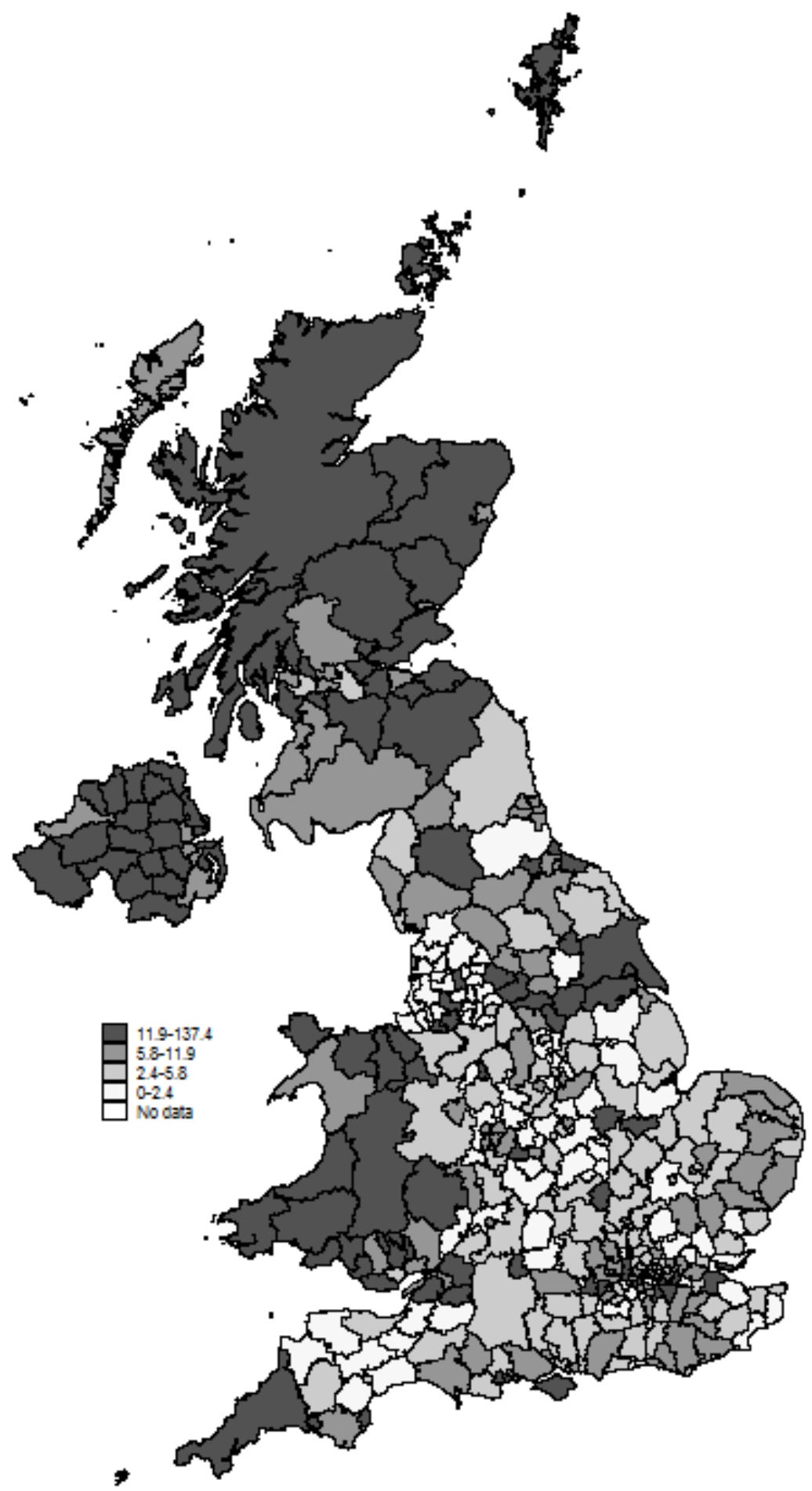

Notes: Produced using the spmap command of STATA with data taken from http://www.wastedataflow.org. 
Table 1: A summary of UK Waste Policy

\begin{tabular}{|l|l|}
\hline Waste hierarchy & $\begin{array}{l}\text { 5p charge for single use bags } \\
\text { distributed by large retailers. }\end{array}$ \\
\hline $\begin{array}{l}50 \% \text { household waste recycling target for the UK } \\
70 \% \text { by } 2025 \text { for Scotland and Wales, } \\
60 \% \text { by } 2020 \text { for Northern Ireland } \\
\text { individual targets set by English local authorities. }\end{array}$ & $\begin{array}{l}\text { Producer Responsibility (Packaging } \\
\text { Waste) Regulations } 2017 \\
\text { Courtauld Commitment } 2025\end{array}$ \\
\hline $\begin{array}{l}£ 80 / \text { tonne landfill tax } \\
\text { Recycling rewards schemes }\end{array}$ & $\begin{array}{l}\text { Hazardous Waste Regulations } \\
\text { (2005) amended in } 2015 \text { covers the } \\
\text { generation and disposal of large } \\
\text { commercial volumes of hazardous } \\
\text { waste. }\end{array}$ \\
\hline
\end{tabular}




\begin{tabular}{|c|c|c|c|c|c|}
\hline \multicolumn{6}{|c|}{$\begin{array}{c}(\mathrm{A}) \\
\text { Kerbside recycling }\end{array}$} \\
\hline Variable & $\begin{array}{l}\text { Estimated } \\
\text { coefficient }\end{array}$ & z-statistic & Variable & $\begin{array}{c}\text { Estimated } \\
\text { coefficient }\end{array}$ & z-statistic \\
\hline$r v_{i t}^{d n k}$ & -0.105 & $-2.67^{*}$ & $m t d_{4 i t}^{d k}$ & 0.0007 & $2.75^{*}$ \\
\hline$w v_{i t}$ & -1.878 & $-16.38^{*}$ & $\mathrm{fr}_{4 i t}^{\mathrm{dk}}$ & -0.016 & $-2.00^{*}$ \\
\hline$X_{1 i t}$ & 11.520 & $7.22^{*}$ & $m t d_{5 i t}^{d k}$ & 0.0001 & 0.73 \\
\hline$X_{2 i t}$ & -8.608 & $-5.61^{*}$ & $f r_{5 i t}^{d k}$ & -0.005 & -1.10 \\
\hline$X_{3 i t}$ & -8.695 & $-5.65^{*}$ & $m t d_{6 i t}^{d k}$ & 0.001 & 0.25 \\
\hline$X_{4 i t}$ & -0.030 & -1.80 & $f r_{6 i t}^{d k}$ & -0.012 & -1.00 \\
\hline$X_{5 i t}$ & 0.006 & $10.35^{*}$ & $m t d_{7 i t}^{d k}$ & 0.001 & $4.16^{*}$ \\
\hline$m t d_{1 i t}^{d k}$ & 0.001 & $2.00^{*}$ & $f r_{7 i t}^{d k}$ & -0.012 & $-2.34^{*}$ \\
\hline$f r_{1 i t}^{d k}$ & -0.006 & -0.44 & $m t d_{8 i t}^{d k}$ & 0.001 & $4.27^{*}$ \\
\hline$m t_{2 i t}^{d k}$ & 0.0004 & 1.10 & $f r_{8 i t}^{d k}$ & 0.0007 & 0.14 \\
\hline$f r_{2 i t}^{d k}$ & -0.012 & -1.13 & $m t d_{9 i t}^{d k}$ & -0.0007 & -1.27 \\
\hline$m t d_{3 i t}^{d k}$ & 0.0005 & $2.03^{*}$ & $f r_{9 i t}^{d k}$ & 0.022 & $4.58^{*}$ \\
\hline$f r_{3 i t}^{d k}$ & -0.019 & $-2.44^{*}$ & $n m t_{i t}$ & 0.017 & $2.86^{*}$ \\
\hline \multicolumn{6}{|c|}{$\mathrm{R}^{2}=0.638$} \\
\hline
\end{tabular}

(B)

Non-kerbside recycling

Variable Estimated z-statistic Variable $\quad$ Estimated $\quad$ z-statistic coefficient coefficient

$\begin{array}{cccccc}r v_{i t}^{d k} & 0.063 & 0.90 & X_{2 i t} & -8.408 & -3.64^{*} \\ w v_{i t} & -0.382 & -2.38^{*} & X_{3 i t} & -8.615 & -3.72^{*} \\ \text { cas }_{i t} & 0.187 & 7.13^{*} & X_{4 i t} & -0.059 & -2.23^{*} \\ X_{1 i t} & 9.691 & 4.08^{*} & X_{5 i t} & 0.005 & 5.64^{*}\end{array}$

$\mathrm{R}^{2}=0.411$

(C)

$\underline{\text { Residual waste }}$

$\begin{array}{cccccc}\text { Variable } & \begin{array}{c}\text { Estimated } \\ \text { coefficient }\end{array} & \text { z-statistic } & \text { Variable } & \begin{array}{c}\text { Estimated } \\ \text { coefficient }\end{array} & \text { z-statistic } \\ r v_{i t}^{d k} & -0.383 & -27.00^{*} & m d_{3 i t}^{w v} & 0.0004 & 2.14^{*}\end{array}$




$\begin{array}{cccccc}r v_{i t}^{d n k} & -0.019 & -1.34 & \mathrm{fr}_{3 i t}^{w v} & 0.003 & 0.77 \\ X_{1 i t} & 5.224 & 7.94^{*} & m d_{4 i t}^{w v} & 0.0008 & 1.20 \\ X_{2 i t} & -3.854 & -5.88^{*} & f r_{4 i t}^{w v} & 0.008 & 2.45^{*} \\ X_{3 i t} & -3.888 & -5.92^{*} & m d_{5 i t}^{w v} & -0.00003 & -0.27 \\ X_{4 i t} & 0.006 & 0.79 & f r_{5 i t}^{w v} & 0.004 & 1.62 \\ X_{5 i t} & 0.002 & 8.45^{*} & m d_{6 i t}^{w v} & 0.0005 & 2.01^{*} \\ m t d_{1 i t}^{w v} & 0.0005 & 3.97^{*} & f r_{6 i t}^{w v} & 0.004 & 0.89 \\ f r_{1 i t}^{w v} & -0.011 & -4.28^{*} & m t d_{7 i t}^{w v} & 0.0003 & 1.55 \\ m t d_{2 i t}^{w v} & 0.0005 & 5.92^{*} & f r_{7 i t}^{w v} & 0.006 & 2.38^{*} \\ \mathrm{fr}_{2 i t}^{w v} & -0.003 & -1.02 & & \end{array}$

Note: 3SLS estimates. Constants not reported to conserve space. * indicates significance at the 5\% level. Number of observations is 3,497. 


\begin{tabular}{|c|c|c|c|c|c|}
\hline \multicolumn{6}{|c|}{$\begin{array}{c}\text { (A) } \\
\text { Kerbside recycling }\end{array}$} \\
\hline Variable & $\begin{array}{c}\text { Estimated } \\
\text { coefficient }\end{array}$ & z-statistic & Variable & $\begin{array}{l}\text { Estimated } \\
\text { coefficient }\end{array}$ & z-statistic \\
\hline$r v_{i t}^{g n k}$ & -0.593 & $-9.03^{*}$ & $m t d_{1 i t}^{g k}$ & 0.005 & $5.05^{*}$ \\
\hline$w v_{i t}$ & -1.202 & $-2.51^{*}$ & $f r_{1 i t}^{g k}$ & 0.010 & 0.39 \\
\hline$X_{1 i t}$ & 3.371 & 0.59 & $m t d_{2 i t}^{g k}$ & 0.240 & 1.95 \\
\hline$X_{2 i t}$ & -0.585 & -0.10 & $f r_{2 i t}^{g k}$ & -0.530 & $-4.76^{*}$ \\
\hline$X_{3 i t}$ & -0.887 & -0.16 & $m t d_{3 i t}^{g k}$ & 0.012 & $7.62^{*}$ \\
\hline$X_{4 i t}$ & -0.354 & $-4.78^{*}$ & $f r_{3 i t}^{g k}$ & 0.041 & 1.43 \\
\hline \multirow[t]{3}{*}{$X_{5 i t}$} & 0.007 & $2.78^{*}$ & $m t d_{4 i t}^{g k}$ & 0.013 & $10.41^{*}$ \\
\hline & & & $f r_{4 i t}^{g k}$ & -0.004 & -0.14 \\
\hline & \multicolumn{5}{|c|}{$\mathrm{R}^{2}=0.086$} \\
\hline
\end{tabular}

(B)

Non-kerbside recycling

Variable Estimated z-statistic Variable coefficient

$\begin{array}{ll}-1.742 & -4.50^{*} \\ -0.412 & -9.03^{*} \\ 0.183 & 3.48^{*} \\ 3.970 & 0.67\end{array}$

Estimated

z-statistic coefficient

$\begin{array}{ll}-1.010 & -0.17 \\ -1.301 & -0.22 \\ -0.504 & -7.21^{*} \\ 0.008 & 3.22^{*}\end{array}$

$$
R^{2}=-0.077
$$

(C)

$\underline{\text { Residual waste }}$

$\begin{array}{cccccc}\text { Variable } & \begin{array}{c}\text { Estimated } \\ \text { coefficient }\end{array} & \text { z-statistic } & \text { Variable } & \begin{array}{c}\text { Estimated } \\ \text { coefficient }\end{array} & \text { z-statistic } \\ r v_{i t}^{g k} & -0.060 & -5.36^{*} & m d_{3 i t}^{w v} & 0.001 & 2.21^{*} \\ r v_{i t}^{g n k} & -0.032 & -1.35 & f r_{3 i t}^{w v} & -0.018 & -1.81^{*} \\ X_{1 i t} & 0.939 & 0.91 & m d_{4 i t}^{w v} & 0.002 & 1.93 \\ X_{2 i t} & 0.200 & 0.19 & f r_{4 i t}^{w v} & -0.010 & -1.59\end{array}$




$\begin{array}{cccccc}X_{3 i t} & 0.150 & 0.15 & m d_{5 i t}^{w v} & 0.0001 & 0.33 \\ X_{4 i t} & 0.008 & 0.46 & f r_{5 i t}^{w v} & 0.006 & 0.73 \\ X_{5 i t} & 0.002 & 5.27^{*} & m t d_{6 i t}^{w v} & 0.0004 & 0.67 \\ m t d_{1 i t}^{w v} & 0.002 & 4.39^{*} & f r_{6 i t}^{w v} & 0.012 & 1.13 \\ f r_{1 i t}^{w v} & -0.027 & -5.38^{*} & m t d_{7 i t}^{w v} & 0.025 & 2.90^{*} \\ m t d_{2 i t}^{w v} & 0.003 & 9.79^{*} & f r_{7 i t}^{w v} & 0.020 & 3.06^{*} \\ f r_{2 i t}^{w v} & -0.051 & -6.11^{*} & & & \\ & & \mathrm{R}^{2}=0.920 & & \end{array}$

Note: 3SLS estimates. Constants not reported to conserve space. * indicates significance at the 5\% level. Number of observations is 3,497 . 